\title{
OBSERVATIONS ON EARLY-SEASON COURTSHIP AND ABORTED NEST-BUILDING IN CEDAR WAXWINGS
}

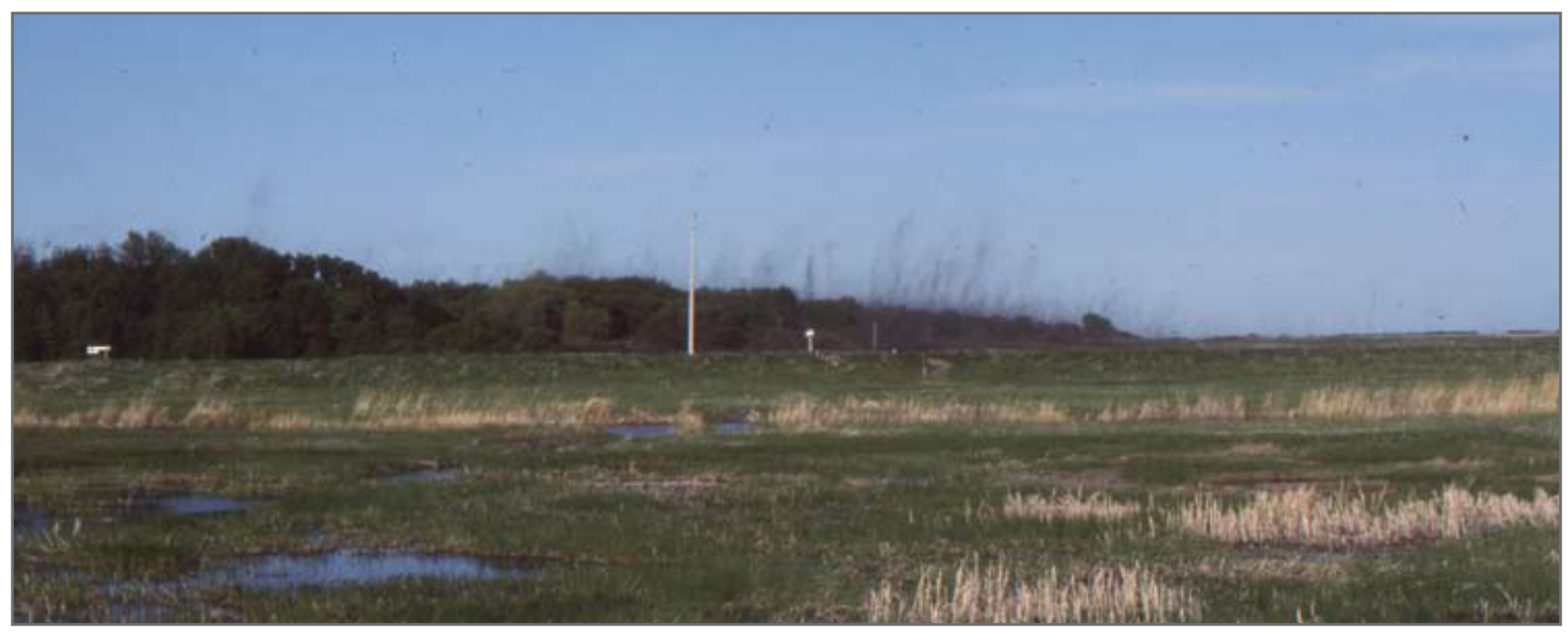

Figure 1. Chironomids (midges) swarming along the south side of the dune-ridge forest, Delta Marsh, Manitoba, mid-June 1986. Delta Marsh is in the foreground.

\section{Spencer G. Sealy}

Department of Biological Sciences

University of Manitoba

Winnipeg, MB R3T 2N2

Spencer.Sealy@umanitoba.ca

A common sight over the course of the breeding season of passerine birds at Delta Marsh, Manitoba, is the vast numbers of adult midges (Insecta: Chironomidae) that emerge from the benthos of wetlands in this area in spring and summer. The massive swarms, sometimes the sum of overlapping emergences, are concentrated above and along the dune-ridge forest that separates Lake Manitoba and Delta Marsh $\left(50^{\circ} 11^{\prime} \mathrm{N}, 98^{\circ} 19^{\prime} \mathrm{W}\right) .^{1}$ The largest swarms are visible to the human eye for distances of up to one kilometre or more (Fig. 1) and are accompanied by an audible hum. ${ }^{2}$ The swarms involve huge numbers of chironomids (hereafter, midges), many of which alight on the vegetation (Fig. 2), sometimes weighing it down. Lacking mouth parts, these insects do not eat, only mate, then die a few days later. ${ }^{2,3}$ Before this happens, however, huge numbers are taken as food by the dozen or so species of songbirds that nest in this riparian forest, for their own nourishment and as food for their young. ${ }^{4-9}$ Some midges are captured in the air, but most are gleaned from the surface of the foliage. ${ }^{9}$

The first large-scale emergences of midges each spring generally occur during the last days of May and/or first days of June (Fig. 3), around the time when most species in the ridge forest begin to lay eggs. ${ }^{4,6-9}$ One exception is the Cedar Waxwing (Bombycilla cedrorum). At Delta Marsh, Cedar Waxwings nest in all or most years but the number of nests varies and the first eggs are not usually laid until late June through July; nestlings in a few nests are still being provisioned after the middle of August. ${ }^{10,11}$

In some years, I observed the sudden appearance of Cedar Waxwings during the last few days of May, usually coinciding with particularly massive emergences of midges. Waxwings fed on the midges, gleaning most from the foliage, but some individuals sallied out from perches to capture them on the wing. I also observed putative males feeding midges one by one to females, who ingested them. These actions differed from one aspect of typical courtship behaviour recorded for this species, in which males and females pass food items back and forth until in many cases females ingest them. ${ }^{12}$

The most interesting observations were of female waxwings that started to build nests (males also contribute to the construction of nests ${ }^{13}$ ) only to stop construction a few days later after the midges had died. The unfinished nests were abandoned and the waxwings left the area. In some years the same or different waxwings returned and initiated clutches in late June and July.

I summarize anecdotal observations of the behaviour of Cedar Waxwings that appeared in the ridge forest during the 
emergence of midges throughout the last days of May and first days of June, and compare them with dates of typical nesting later in the season.

\section{Methods}

The observations of Cedar Waxwings presented here were made during studies of the reproductive and foraging ecology and diets of songbirds in the dune-ridge forest (mid-May to mid-August, 19741986) and over the first several years of a study of the interactions between the brood-parasitic Brownheaded Cowbird (Molothrus ater) and hosts (mid-May through July or mid-August, 1987-1996).

An important part of the work at the outset was regular sweep-net sampling of the foliage conducted by students to quantify the availability of invertebrate prey over the course of the songbirds' breeding seasons. ${ }^{4,6-9}$ This sampling revealed the emergence of adult midges in late May and the first days of June in most years, and serves as a backdrop for the observations presented below. A sample of sweep-net results is given in Figure 3, based on work conducted by G.C. Pohajdak in the ridge forest in 1982-1984. ${ }^{9}$ Those results reveal a preponderance of midges among the invertebrate fauna in late May and early June in 1982 and 1984, and in early June, $1983^{9}$ (Fig. 3).

Clutch-initiation dates of unmarked Cedar Waxwings were obtained opportunistically in the ridge forest at four nests (1981 [n = 1], 1986 [2], 1996 [1]), whereas 29 dates were recorded at nests inspected through incubation and nestling stages during a study of host nest defense (1989 and 1990) ${ }^{14}$, and at six nests inspected through clutch completion in a study of time of day of egg laying (1992). ${ }^{15}$ Clutch-initiation dates of nests

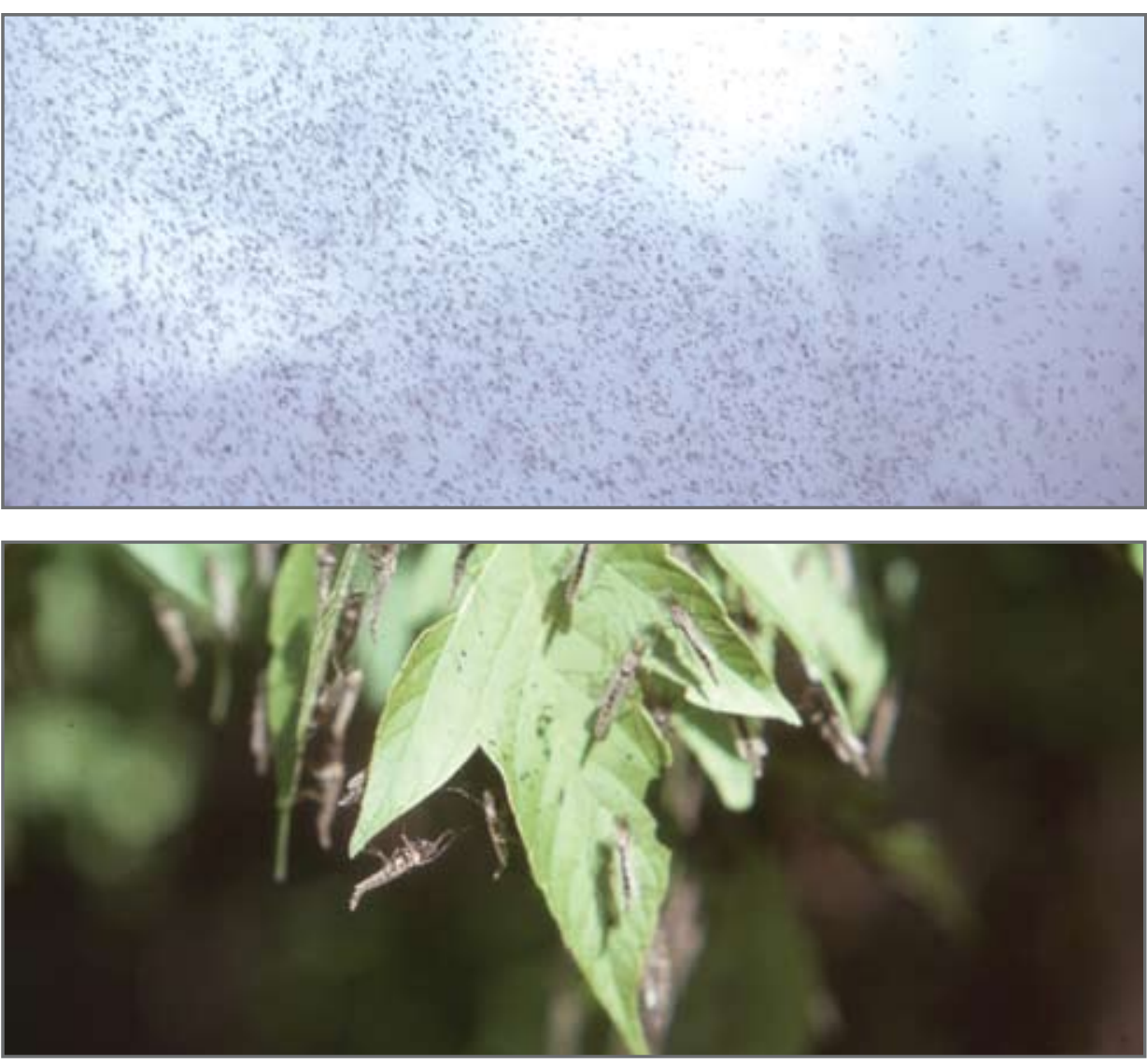

Figure 2. (Above) swarming midges; (below) adult midges alighted on foliage

whose clutches were complete when discovered were calculated by backdating 17 days from the determined date of hatching -5 days for laying (1 egg/day) plus the 12-day mean incubation period. ${ }^{12}$ For nests with nestlings, clutch-initiation dates were calculated by back-dating 37 days from the approximate date of nest departure, based on a 15-day average nestling period plus the 22 days of the egg stage given above. The 39 clutch-initiation dates plus dates of five aborted nests (noted in the observations summarized below) are plotted in weekly periods in Figure 4. These dates reveal a separation of about three weeks between aborted and most active nests, i.e., nests that received at least one egg.

\section{Observations}

1977 - This was the first year in which I recorded an influx of Cedar Waxwings into the ridge forest at the end of May. Waxwings were observed gleaning midges from the foliage by May 28 , but courtship feeding was not observed. Nevertheless, construction of two nests was under way on May 31, about $15 \mathrm{~m}$ apart in Manitoba Maples (Acer negundo). The outer shells appeared nearly complete, although I could see through parts of them. Construction on these nests had not progressed when I viewed them from a distance two days later, to minimize disturbance, but they had been abandoned.

1981 - I did not detect an influx of Cedar Waxwings in the ridge forest this year, but an incomplete nest discovered on June 13 had been abandoned. Laying was recorded in the only active nest inspected in 1981, on June 16, one of the two earliest clutch-initiation dates recorded among all nests (Fig. 4). Midges had been abundant in the ridge forest since the middle of May. ${ }^{7}$ 


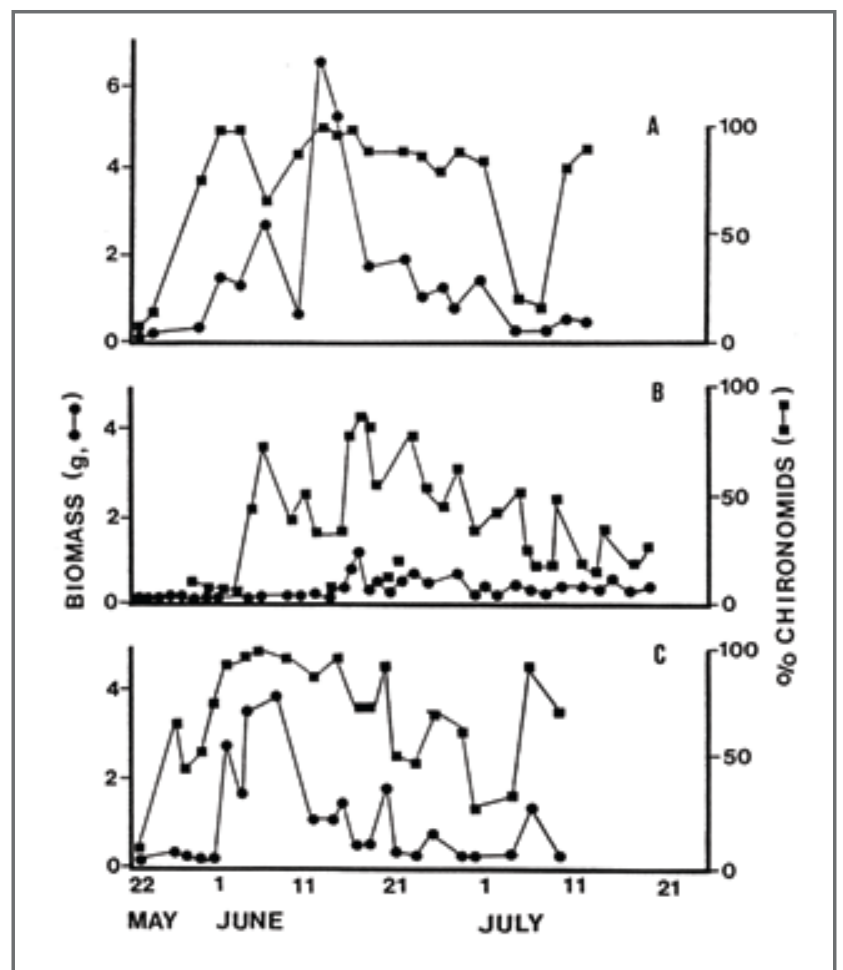

Figure 3. The total biomass (dry weight, $g$ ) of invertebrates sampled by sweep-netting in the dune-ridge forest, Delta Marsh, Manitoba, and the proportion of the biomass that was due to adult midges (A, 1982; B, 1983; C, 1984). Data are from figure 6 (page 29), of Pohajdak. ${ }^{9}$

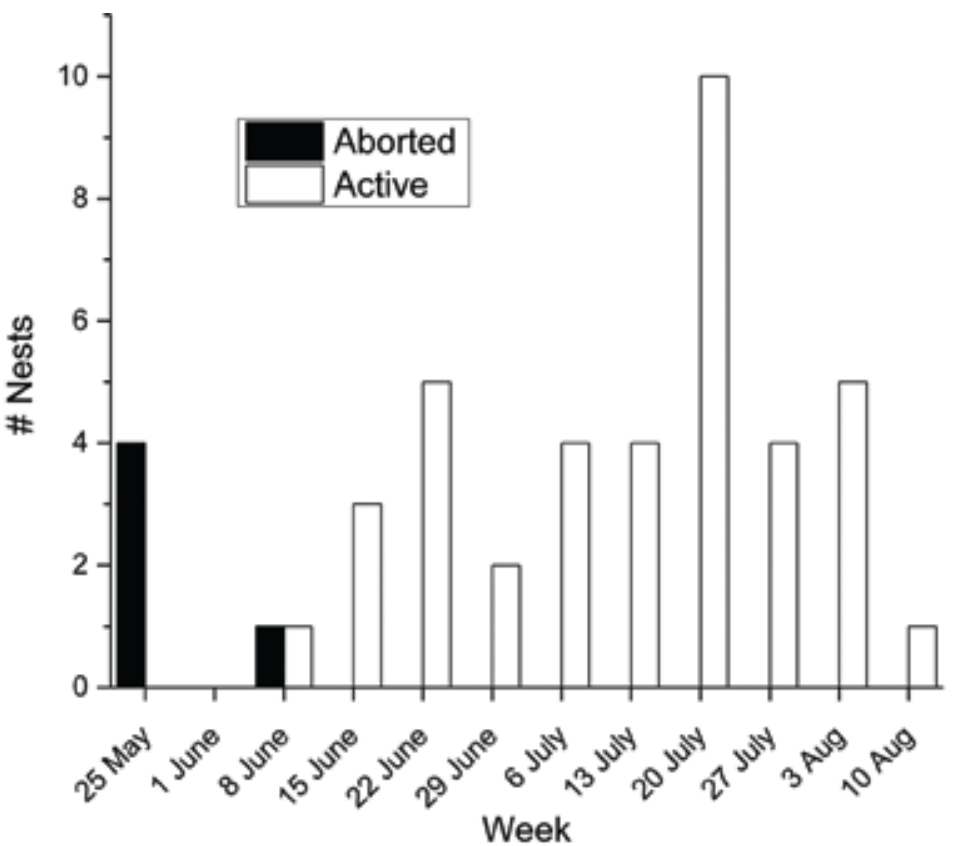

Figure 4. Dates of nests aborted during the early building stage (solid bars) and clutchinitiation dates of Cedar Waxwings (open bars), dune-ridge forest, Delta Marsh, Manitoba. Aborted nests were recorded in 1977 (2 nests), 1981 (1) and 1985 (2); clutch-initiation dates were recorded in 1981 (1 nest), 1986 (2), 1989 (18), 1990 (8), 1991 (4), 1992 (5),
1982 - An influx of flocks of Cedar Waxwings in the ridge forest (one flock was of $~ 50$ individuals) occurred as midges were beginning to emerge on May 30, but the waxwings were gone by June 5 before the midges had dropped out of the sample (Fig. 3). I observed waxwings taking midges but not building nests, at least on the portion of the ridge forest I regularly traversed that spring.

1983 - Cedar Waxwings were present during an emergence of midges June 6 to 8 but neither courtship feeding nor nest construction was observed before the birds disappeared.

1985 - On May 26, during overlapping emergences of midges, I observed a putative male Cedar Waxwing feeding a midge to another waxwing, before the second individual, apparently a female, carried a piece of material to a nest-start on a branch of a Manitoba
Maple. The next day the waxwings were gone and the nest was abandoned, despite the continuing emergence of midges. A repeat of this scenario, although likely involving different birds, occurred on May 31 , during the same emergence of midges. A Cedar Waxwing picked up material in a Peach-leaved Willow (Salix amygdaloides) and carried it to a nest-start in a nearby maple. Joined by another waxwing, the original bird then flew down the ridge forest and out of my sight. The waxwings were not observed again and this nest, which also was never finished, was abandoned. Eleven active nests were recorded in my field notes in July but the contents were not inspected.

1991 - Emerging adult midges were conspicuous from May 24 to 30 , but I did not record Cedar Waxwings in the portion of the ridge forest I regularly traversed until clutches at four nests were initiated between July 20 and 24.

\section{Discussion}

The appearance of Cedar Waxwings in the dune-ridge forest in late May is consistent with springarrival dates recorded elsewhere in Manitoba ${ }^{16,17}$, including Criddle's records from the southwestern portion of the province, compiled a century ago. ${ }^{18}$ Egg dates derived from the Prairie Nest Records Scheme summarized in The Birds of Manitoba spanned the period June 11 to August $19,{ }^{17}$ compare similarly to the span of clutch-initiation dates of June 11 to August 6 in the dune-ridge forest (Fig. 4), or August 23, when days of egg laying and incubation are included.

What is apparently unappreciated, however, is the initiation of nest construction by Cedar Waxwings around the time of spring arrival, apparently in response to a pulse of abundant but ephemeral prey, followed by the abandonment of unfinished nests. Cedar Waxwings 
apparently move widely and possibly sample the food supply before settling down to nest behaviour that reflects the species' lower tendency to return to the same breeding sites in subsequent years. ${ }^{12}$ Early nests take five to six days for construction ${ }^{12}$, therefore, construction of nests that received eggs by June 11 would have been initiated by June 5 or 6 , and confirm that some of the earliest nests of the season do become active. Their infrequency, however, dictates caution when confirming their status.

Cedar Waxwing nests have been reported in May, but in these cases it was not determined whether eggs were laid, i.e., the nests had become active. For example, in The Birds of Manitoba, an early nest was noted under construction on May 27 (year not given), but it was apparently not determined whether it received eggs or had been abandoned before completion. ${ }^{17}$ In Birds of the Saskatoon Area, an "[a]ctive nest" was observed on the early date of May 22, $1973^{19}$, but its status also was not confirmed.

Nest abandonment by Cedar Waxwings has been recorded frequently by other investigators ${ }^{12,13,20}$ but the stimulus for desertion is difficult to pinpoint - whether it is disturbance at the nest by the investigator, interaction of adult waxwings with potential predators, inclement weather, a change in food availability, parasitism by the Brownheaded Cowbird, or some other factor. 12,14,20,21 In a five-year study of breeding Cedar Waxwings in Ohio, 60 of 144 nesting attempts (42 per cent) failed during the nest-building stage, 55 per cent due to bad weather, whereas the other nests had not received eggs ${ }^{12}$, possibly having been aborted early in the season, although this was not stated. Observations at Delta Marsh and those published in other studies of Cedar Waxwings and other species of songbirds during the breeding season reinforce the need for careful observations, preferably backed up by controlled experiments in the field, before ascribing a cause of the abandonment. $^{21}$

\section{Acknowledgements}

I am indebted to former graduate students, J.V. Briskie, D.G. Busby, D.M. Guinan, and G.C. (Biermann) Pohajdak, whose studies of foraging and diet ecology of passerine birds in the dune-ridge forest provided the backdrop for the observations presented here. Todd J. Underwood prepared the graph of the nest dates and J. Paul Goossen offered constructive comments on the manuscript. Research conducted at Delta Marsh over the years was funded chiefly by the Natural Sciences and Engineering Research Council of Canada, augmented by important in-kind support provided by the Delta Marsh Field Station (University of Manitoba).

1. MacKenzie DI (1982) The dune-ridge forest, Delta Marsh, Manitoba: Overstory vegetation and soil patterns. Canadian FieldNaturalist 96:61-68.

2. Tripplehorn CA, Johnson NF (2005) Borror and DeLong's Introduction to the Study of Insects, 7th edition. Thomson Brooks/Cole, Belmont, CA.

3. Bland RG (1978) How to Know the Insects William Brown, Dubuque, IA.

4. Busby DG, Sealy SG (1979) Feeding ecology of a population of nesting Yellow Warblers. Canadian Journal of Zoology 57:1670-1681.

5. Sealy SG (1980) Reproductive responses of Northern Orioles to a changing food supply. Canadian Journal of Zoology 58:221-227.

6. Biermann GC, Sealy SG (1982) Parental feeding of nestling Yellow Warblers in relation to brood size and prey availability. Auk 99:332-341.

7. Guinan DM, Sealy SG (1987) Diet of House Wrens (Troglodytes aedon) and the abundance of the invertebrate prey in the dune-ridge forest, Delta Marsh, Manitoba. Canadian Journal of Zoology 65:1587-1596.

8. Briskie JV, Sealy SG (1989) Determination of clutch size in the Least Flycatcher. Auk 106:269-278.

9. Pohajdak GC (1988) Feeding guilds, diets and foraging behavior of insectivorous passerines in a riparian habitat in Manitoba. Ph.D. dissertation, University of Manitoba, Winnipeg.

10. Neudorf DL (1991) Nest defense in four host species of the Brown-headed Cowbird (Molothrus ater). M.Sc. thesis, University of Manitoba, Winnipeg.

11. Sealy SG (2016) Additional observations of putative host species feeding only cowbird fledglings. Blue Jay 74(3):28-31.

12. Putnam LS (1949) The life history of the Cedar Waxwing. Wilson Bulletin 61:141-182.

13. Mountjoy DJ, Robertson RJ (1988) Nestconstruction tactics in the Cedar Waxwing. Wilson Bulletin 100:128-130.

14. Neudorf DL, Sealy SG (1992) Reactions of four passerine species to threats of predation and cowbird parasitism: enemy recognition or generalized responses? Behaviour 123(12):84-105.

15. McMaster DG, Neudorf DLH, Sealy SG, Pitcher TE (2004) A comparative analysis of laying times in passerine birds. Journal of Field Ornithology 75:113-122.

16. Taylor P (1983) Wings along the Winnipeg: The Birds of the Pinawa-Lac du Bonnet Region, Manitoba. Manitoba Naturalists Society, Eco Series Number 2.

17. Bouchart M, Taylor P (2003) Cedar Waxwing. Page 314 in The Birds of Manitoba. Manitoba Naturalists Society, Winnipeg.

18. Criddle N (1922) A calendar of bird migration. Auk 39:41-47.

19. Wooding, L (2002) Cedar Waxwing. Page 244 in Leighton AL, Hay J, Houston CS, Roy JF, and Shadick S (Editors). Birds of the Saskatoon Area. Nature Saskatchewan, Number 5 (Manley Callin Series), Special Publication Number 23.

20. Tyler WM (1950) Bombycilla cedrorum (Vieillot), Cedar Waxwing. Pages 79-102 in Bent AC (Editor). Life Histories of North American Wagtails, Shrikes, Vireos and their Allies. U.S. National Museum Bulletin, Number 197

21. Rothstein SI (1976) Experiments on defenses Cedar Waxwings use against cowbird parasitism. Auk 93:675-691. 